\title{
3. Building theory in a practical science
}

\author{
SHIRLEY GREGOR \\ AUSTRALIAN NATIONAL UNIVERSITY
}

\section{Abstract}

The aim of this chapter is to consider the problem of theory building in a practical science and in information technology (IT) and information systems (IS) in particular. Theorising in IT design disciplines (practical science) is differentiated from theorising in other scientific fields in essential ways. Two modes of theorising are distinguished for design disciplines: an interior mode with the how of artefact construction studied and an exterior mode with the what of existing artefactual phenomena studied. Eight principles of theorising are advanced for theory building: 1) artefact centrality; 2) artefact purposefulness; 3) artefacts as systems; 4) design research variants; 5) differing logics; 6) types of theory; 7) mid-range theorising; and 8) interior and exterior modes for theorising. The implicit claim is that consideration of these principles will improve theorising in design disciplines - for both design researchers and researchers using more traditional methods. Some illustrative applications are provided in support of this claim.

\section{Introduction}

A tension between pure and applied branches of knowledge has long been recognised and can be traced back to the distinction between epistêmê and technê by the Greek philosophers. More recently, a distinction has been drawn between the paradigm of 'science' and that of the 'artificial sciences'. The science paradigm can be categorised by terms such as epistêmê, pure science or the explanatory sciences, while the 'sciences of the artificial' paradigm has invited labels such as technê, applied science, prescriptive science, design science, technology and even on occasion art or craft. The distinction between 
the two paradigms rests on the characteristics of the traditional sciences, which concern 'what is', and the sciences of the artificial, which concern 'what could be' - the development of artefacts through human agency (Simon 1996). The traditional-science paradigm represents the dominant mode of thinking in the philosophy of science and it is comparatively rare to find any comprehensive account of how knowledge and theory might be developed in applied branches of knowledge, including those that deal with technology, such as information systems (IS) (see O'Hear 1989). The purpose of this chapter is to help redress this imbalance, by considering how theory can and should be developed in the artificial-sciences paradigm, with a focus on fields of study concerning information technology (IT).

This chapter considers theory generation in both an interior mode - in the design and development of the inner environment of artefacts - and an exterior mode, in which the artefacts are theorised about in their outer environment. These two modes are seen as two sides of a coin; they are intertwined and both contribute to the development of theory concerning artefacts in the sciences of the artificial. This chapter differs from prior work in that it applies not only to researchers who personally develop artefacts and theorise about the results in the interior mode (as in some conceptions of 'design science'), but to researchers who carry out more traditional theorising in the exterior mode in a manner common in mainstream journals. An implication of the chapter is that theorising in both modes can be improved by taking account of underlying principles that arise from the unique characteristics of the fields of study that concern IT artefacts.

Figure 3.1 is provided at this point as an orienting device for the argument in the remainder of the chapter, in which the perspective it represents will be explained in more detail. It shows the interior and exterior modes of theorising within an IT design discipline as well as the connections to reference theories in other design disciplines and in the science paradigm.

Although research and theorising in relation to design science are increasingly dealt with (for example, Hevner et al. 2004; March and Smith 1995; Simon 1996; van Aken 2004, 2005; Venable 2006), the question of theory building is still relatively unexplored. Further, discussion of theory building in the artificialscience paradigm is complicated by the fact that theory building in general is poorly understood. In reviewing the literature on the activities that go on during theory construction, Weick (1989:517) notes that 'the literature on this topic is sparse and uneven and tends to focus on outcomes and products rather than process'. 


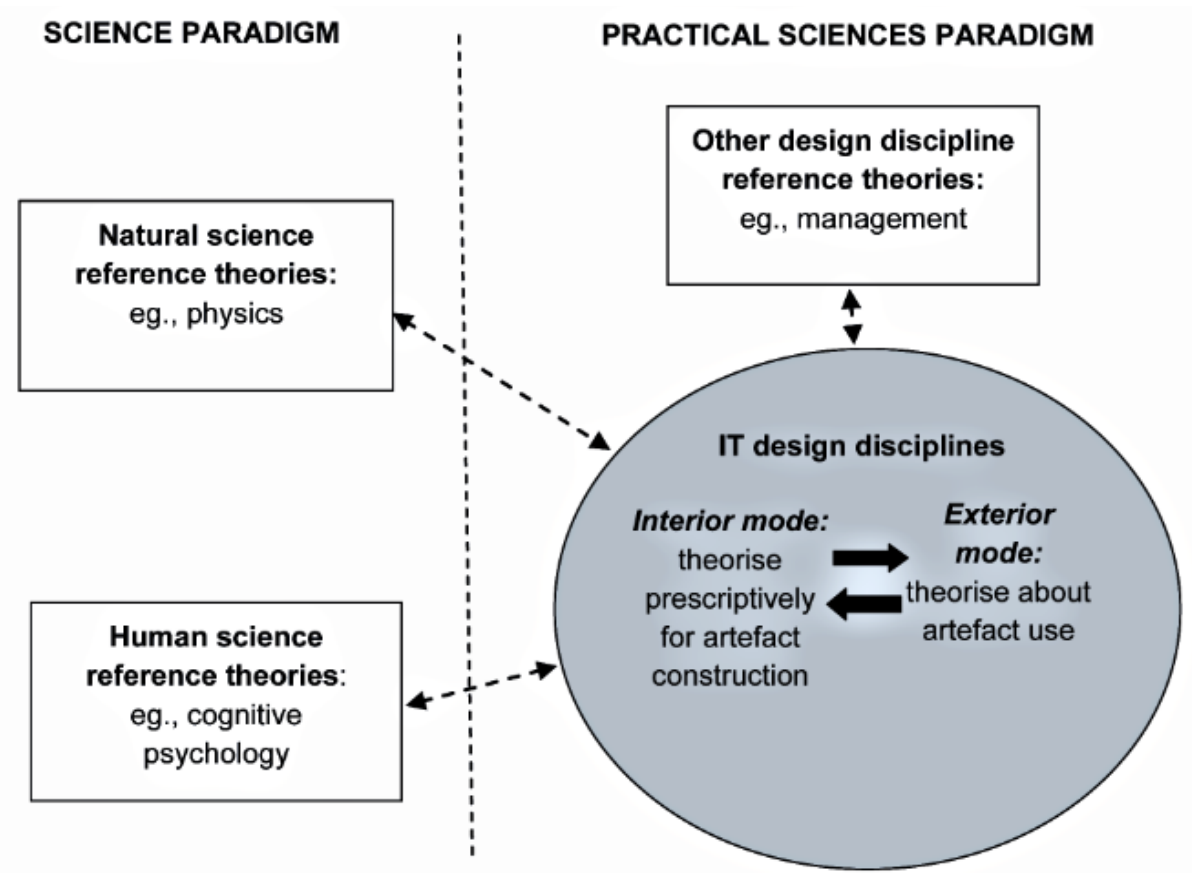

Figure 3.1 A framework for understanding theory building in IT as a practical science

In discussing theory building, we are studying a human activity, undertaken by researchers whose aim is to contribute to human knowledge. A broad view of theory itself is adopted. Theory is seen as knowledge that has some degree of abstraction and generalisability and consists of statements about relationships among constructs within some specified boundaries. The type of statements made can depend on the type of theory. Congruent with Gregor (2006), five interrelated different types of theory are recognised: Type 1-theory for analysing; Type II - theory for explaining; Type 3-theory for predicting; Type IV - theory for explaining and predicting; and Type $\mathrm{V}$ - theory for design and action. Here, we consider all five types of theory from within the perspective of the sciences of the artificial.

The terms 'sciences of the artificial', 'artificial-sciences paradigm' and 'design paradigm' are used in this chapter in the sense used by Simon (1996) to refer to the disciplines that are concerned with artificial, human-made phenomena, including administration, engineering, medicine, business, architecture and art. Strasser (1985) offers the alternative term of 'practical sciences' for these fields. The term 'design science' is used for the subset of research activities that more directly concerns the design and construction of particular artefacts (as in Hevner et al. 2004; March and Smith 1996). 
The contribution of this chapter is that it brings together thinking about theory building in the design paradigm that has, until now, been relatively piecemeal. The chapter has practical relevance in that it focuses on building theory that concerns the design, construction and use of artefacts in some way-knowledge that has real-world utility. The chapter has implications for research practice in that it assists researchers by clarifying some of the issues around theory building itself - a thorny problem for both new and experienced researchers and one that is particularly poorly addressed from an applied-science perspective.

The focus of the chapter is on artefacts that relate to IT (computers) and the computing disciplines-identified as computer engineering, computer science, IS, IT and software engineering (CC2005 2005). Much of the discussion, however, is couched in terms that apply to IS. The artefacts that are of interest are of many types and include both products (databases, electronic markets, web sites) and processes (IT management strategies, modelling methods) (see Gregor and Jones 2007).

The chapter proceeds as follows. The next two sections provide further discussion of the two paradigms of science and artificial science and some underlying ideas for theory building in general. In the next section, the unique features of the IT discipline that cause its theorising to have distinct characteristics are presented, followed by eight principles that it is argued underlie this theorising. These principles were derived analytically from the characteristics of the discipline and a study of prior literature. Some concluding remarks end the chapter.

\section{Two paradigms}

The issue of the relationship between the pure and applied fields of human inquiry has a distinguished lineage, as shown by the attention the Greek philosophers devoted to the problem. Loosely understood in modern terms, epistêmê, or knowledge, was distinguished from technê, or practice. Aristotle spoke of epistêmê in terms that could be equated to the modern understanding of scientific knowledge. That is, scientific knowledge concerns objects that do not admit of change; these objects are eternal and exist from necessity (Parry 2007). In this treatment, scientific knowledge implies a deductive system with the relations among terms both invariable and necessary. On the other hand, technê concerns the bringing into existence of something that could either exist or not exist - that is, the contingent. Further, each technê aims at some end-for example, health is the end of medicine. A close relation between technê and epistêmê is also recognised, although not without some ambiguity. Again using 
the example of medicine, Aristotle spoke of medicine as an epistêmê because the physician studies health, but also as a technê because the physician produces health.

The distinction between pure and applied branches of knowledge has continued, although the close interrelationship among the two has also continued to be recognised. Nevertheless, it is probably fair to say that the philosophy of science as a whole has been fairly firmly rooted in epistêmê-type thinking, rather than concerning itself with the knowledge that relates to technê. For example, Nagel's work The Structure of Science (1979) makes practically no reference to applied science or to technology. As late as 2003, Scharff and Dusek produced an anthology of readings - the Philosophy of Technology - in order to address a perceived 'widespread failure to question the relation between contemporary technology and modern science' (p. x.). The argument developed in this chapter is that the neglect of applied science and technology in the philosophy of science has meant that some important aspects of thinking about how knowledge and theory are developed for the sciences of the artificial have been overlooked. ${ }^{1}$

It is helpful to look at some of the distinguishing features of the two paradigms (see Table 3.1). The salient difference is that the sciences of the artificial are concerned with the study of artefacts, 'things' that are constructed by human beings in order to achieve some end, goal or purpose. Strasser (1985:59) defines a practical science as a 'science which is conceived in order to make possible, to improve, and to correct a definite kind of extra-scientific praxis'. Note that the wall between the two paradigms is permeable, as there will be researchers working primarily in one paradigm who also have an interest in the other. For example, scientists in biology include plant biologists designing new strains of wheat. Conversely, researchers in the applied-science paradigm might develop artefacts that influence theorising in the science paradigm, as when newly developed computer systems were used by cognitive psychologists as a means of understanding human memory processes. The distinction drawn by Strasser between an applied science and a practical science is that in the former the science is 'accidentally' applied to a practical issue, whereas in practical sciences such as agriculture the essential aim is towards a definite kind of praxis.

\footnotetext{
1 The history of the philosophy of science is worthy of close regard. The degree of emphasis on inductivism versus deductivism and empiricism versus rationalism and the degree of recognition for the need for creativity and imagination in scientific thinking have swung one way and then the other. What is of interest for this chapter are the definitive shifts in focus as to the phenomena of study. In the time of the ancient Greeks, philosophy included all branches of knowledge. The emphasis on the natural sciences and even the coining of the word 'scientist' accompanied the age of enlightenment in the eighteenth century. Another major shift can be distinguished with the distinction drawn by Dilthey (1883) between the natural and human sciences. The author believes another major shift has begun with the emphasis since the later part of the twentieth century on design or practical sciences, in which the phenomena of interest are artefacts (Simon 1996; Strasser 1985).
} 
The consequences of what a study of artefacts means for theory building are discussed in detail in the following sections.

Table 3.1 The science and the artificial-science paradigms

\begin{tabular}{|l|l|l|}
\cline { 2 - 3 } \multicolumn{1}{l|}{} & Paradigm \\
\hline Features & Science & $\begin{array}{l}\text { Practical science/sciences of the } \\
\text { artificial }\end{array}$ \\
\hline Foci of interest & $\begin{array}{l}\text { Naturally occurring } \\
\text { phenomena, 'as is', the } \\
\text { necessary }\end{array}$ & $\begin{array}{l}\text { Designed artefacts, 'what can } \\
\text { be', the contingent }\end{array}$ \\
\hline Distinguishing feature & Observation of phenomena & $\begin{array}{l}\text { Creation and observation of } \\
\text { artefacts }\end{array}$ \\
\hline Discipline examples & $\begin{array}{l}\text { Astronomy, biology, } \\
\text { chemistry geology, physics, } \\
\text { sociology }\end{array}$ & $\begin{array}{l}\text { Accounting, art, computer } \\
\text { science, design, economics, } \\
\text { engineering, ethics, information } \\
\text { systems, management, } \\
\text { marketing, medicine }\end{array}$ \\
\hline
\end{tabular}

After Simon (1996)

\section{Theory building in general}

Some fairly basic ideas inherited from science about theory building continue to be influential in the artificial sciences and to some extent are adopted unquestioningly. As the discussion below indicates, this uncritical attitude might not be a good thing.

A key influence has been an idealised view of the scientific process known as the 'hypothetico-deductive method' (see Godfrey-Smith 2003:70), which contains the following steps.

- Step 1: conjectures are generated, possibly as a result of observations.

- Step 2: observational predictions (hypotheses) are deduced from the conjectures.

- Step 3: if predictions match the hypotheses, the theory is supported; if not, the theory is not supported and should be rejected.

The idea of theory building itself can be interpreted in differing ways. In a narrow sense, the term could refer to Step 1 - the process of arriving at hypotheses that can then be tested. This narrow sense will be referred to as 'theory generation' in the remainder of this chapter. In a wider sense, 'theory building' can be taken to refer to the overall process in which there are cycles of 
activities including observation, hypothesising, testing and theory refinement or extension, with the resultant theory becoming stronger in successive cycles and increasing in explanatory and predictive power.

Divergent thinking about even the simple hypothetico-deductive model can be found among philosophers of science. Karl Popper (1980) notably had little interest in where conjectures came from in the first place and was also opposed to the idea that theories became 'stronger' as they survived more and more tests, owing to the problems with inductive reasoning. That is, strictly speaking, one cannot infer by inductive reasoning from any large number of observations in the past, or any amount of theorising, that a new observation will conform to what has already occurred (the next swan might indeed be black). Although inductive scepticism has a place, in practice, the philosophy of science has moved on and there are now more varied views on how theory development can occur. There is greater recognition that theories develop and are extended in a cumulative fashion over time and that theories that have a greater weight of evidence behind them and have survived more thorough testing are to be preferred to other, less well-tried theories (Godfrey-Smith 2003).

Further, more recent work has treated inductive reasoning more favourably for theory building in the narrow sense (Step 1). Examples include the grounded theory work of Glaser and Strauss (1967). Merton (1968:47), writing about sociological theory, advocates the development of theory of the middle range and the building of theory on an adequate base of 'antecedent empirical enquiry'. Merton (1968:39) defines theories of the middle range as '[t]heories that lie between the minor but necessary working hypotheses that evolve in abundance during day-to-day research and the all-inclusive systematic efforts to develop a unified theory that will explain all the observed uniformities of social behaviour, social organization and social change'.

Merton saw the development of mid-range theories as a more achievable aim in emerging disciplines, the state of affairs in much of established science and a necessary step on the way to increasingly comprehensive theory.

The management literature also provides some discussion of the processes of theory building. Kaplan (1964) distinguishes between theory growth 'by intention', when a new theoretical explanation is given for a wide region, and theory growth 'by extension', when theory from one smallish region is extended to adjoining regions in a piece-by-piece manner. Bourgeois (1979) provides a description whereby theory of the middle range is generated in a non-linear process with seven steps: 1) the topic of investigation is identified; 2) the method of theory generation is explicated; 3) literature is reviewed; 4) theory is generated by induction from an empirical base; 5) theory is extended 
with deduction of propositions; 6) metaphysical elaboration; and 7) conclusions. Steps 3, 4 and 5 occur concurrently rather than sequentially. Weick (1989) sees theory construction as 'disciplined imagination'.

There has also been some work on how theory is developed when the field of inquiry is treated as a science concerned with artefacts. Van Aken $(2004,2005)$ calls for the distinguishing in management studies of 'management theory', a design science that has as its goal the development of 'field-tested and grounded technological rules'. The technological rule is part of a mid-range theory with a validity limited to a specified application domain. Venable (2006) proposes ideas for both the form and the details required of theory in design science and also a framework for the interaction of design science with other scientific paradigms. Goldkuhl (2004) proposes a framework for the multi-grounding of design theory empirically, theoretically and internally. These sources and others are drawn on in advancing the principles in the next section.

\section{Principles for theory building in IT-related disciplines}

This section proposes a number of principles that it is argued underlie all theorising in the design fields related to IT. The main thrust of the argument, however, is couched in terms that relate to IS - a field that requires some knowledge of technology, but also knowledge from the behavioural sciences. It is acknowledged that aspects of the argument could be less applicable to areas in which the human behavioural aspects of technological use are less, or not at all, salient (for example, computer engineering).

For a number of reasons, the fields of study relating to IT require their own unique examination of how theorising is carried out. In brief

- IT is not natural science, yet natural science is implicated in design; IT concerns designed artefacts and belongs to the artificial-sciences paradigm, as argued above; knowledge from science is implicated in that the IT artefacts constructed conform to physical laws

- IT disciplines are not social or behavioural (human) science, although the social sciences are implicated in design, in that their knowledge can help explain interactions between IT and individuals and groups and inform the design of artefacts; yet the social sciences are not, for the most part, design disciplines

- IT disciplines differ from other design disciplines. IT artefacts are different because they concern complex systems, whereas artefacts dealt with in many other design disciplines are not. 
These three characteristics taken together mean that the IT discipline is unique. Other disciplines deal with complex systems - for example, biology - but the systems (mostly) are not constructed by human agency. Other design disciplines deal with complex systems - for example, management and economics - but their artefacts are not based on technologies that are based in physical science. Possibly the closest discipline that matches the characteristics of IT is medicine, in which there are designed artefacts, such as drugs, that conform to scientific analysis, but there are also interventions with human beings, and knowledge of biological and behavioural sciences is required. Perhaps a difference still occurs in that the medical artefacts are not themselves complex systems. Further, the natural sciences are relied on (biology and physiology) rather than the physical sciences (electronics).

It is argued that eight principles that arise from these three defining characteristics underlie theory building in IT disciplines. These principles were derived from consideration of the defining characteristics of IT as a design discipline above, supplemented by an analysis of the extant literature relating to theory building.

Each principle is presented with some illustrative examples of what the principle means to research practice. Table 3.2 provides an overview of the principles. These principles are meant to apply both to researchers focusing on artefact construction, in an interior mode, and to researchers theorising about artefacts from the outside in an exterior mode (see Principle 8).

\section{Table 3.2 Principles for theory building in a design discipline}

\begin{tabular}{|l|l|l|}
\hline No. & \multicolumn{2}{|l|}{ Key idea } \\
\hline 1 & Artefact centrality & IT artefacts are central to theorising \\
\hline 2 & Artefact purposefulness & $\begin{array}{l}\text { Purposefulness of IT artefacts is recognised and outcomes } \\
\text { studied }\end{array}$ \\
\hline 3 & Artefacts are systems & IT artefacts are systems (or involved with systems) \\
\hline 4 & Design research variants & $\begin{array}{l}\text { The range of design research approaches should be } \\
\text { recognised }\end{array}$ \\
\hline 5 & Differing logics & Different logics are needed \\
\hline 6 & Types of theory & $\begin{array}{l}\text { Different types of theory are needed, including design } \\
\text { theory }\end{array}$ \\
\hline 7 & Mid-range theorising & Mid-range, well-grounded theorising is of particular value \\
\hline 8 & $\begin{array}{l}\text { Interior and exterior } \\
\text { modes }\end{array}$ & Theorising is done in both interior and exterior modes \\
\hline
\end{tabular}




\section{Principle 1: IT artefacts are central to theorising}

In this chapter, by definition, IT design disciplines such as IS concern artefacts and we would expect to find an artefact playing a central role in theorising. This point has been argued by others, including Benbasat and Zmud (2003), Iivari (2003), Orlikowski and Iacono (2001) and Weber (1987).

This principle distinguishes theory that belongs to IS from reference or kernel theories - theories that can be useful in the study of artefacts, as explanations for artefact behaviour or for design ideas, but which do not have an IT artefact as a primary focus. An example is a theory of interpersonal trust, which belongs as a reference theory to the social sciences, whereas theory about how trust is engendered in online communications could belong to IS.

\section{Practical application}

Research work is more likely to find acceptance in IT publication outlets if it concerns theory relating to IT artefacts. In IS, the leading journal, MIS Quarterly, has as its objective the enhancement and communication of knowledge concerning the development of IT-based services, the management of $I T$ resources, and the use, impact, and economics of $I T$ with managerial, organizational, and societal implications' (MIS Quarterly 2008; emphasis added). Although professional issues affecting the IS discipline are also dealt with, the key message is that papers should relate to IT artefacts in some way. Personal experience as an editor has shown the author that papers are likely to be rejected if they relate more to a reference discipline than to IS. A paper that purports to deal with knowledge-management systems but deals only with scenarios regarding knowledge sharing and not with any features of a technology-based system is unlikely to be accepted.

\section{Principle 2: purposefulness of IT artefacts is recognised and outcomes studied}

A distinguishing feature of an artefact is that it serves some purpose, although purposes can be many and varied. For example, an ornament has ornamentation as its purpose. This concept dates back to Aristotle in his depiction of the causa finalis - the final cause or end of an artefact, 'what it is for', one of the four causes of any thing (Hooker 1993). The artefact's purpose relates to the context in which it is used. Heidegger (1993) gives the example of a silver chalice, of which, in order to understand its purpose, we need to understand the religious ritual in which the chalice is to be used. The purpose of the artefact might not 
always be that of the original designer and some of its uses and effects could be unintended. Nevertheless, in studying artefacts, it is needful to consider the goal, end or aim of the artefact as originally intended or as arising in use.

Further, given this distinguishing feature, theorising tends to be more satisfactory if some assessment is made of the outcomes of the artefact's use: whether it achieves a goal or purpose in some way. The constructor of artefacts is expected usually to give some demonstration that the artefact at least works. The observer of artefacts will often evaluate the efficacy or consequences of its use.

This idea finds varied expression across a number of fields. In medicine, the evidence-based approach uses the PICO model, in which $\mathrm{P}$ stands for patient or population, I for intervention (drug or procedure), C for comparison (against what alternatives) and $\mathrm{O}$ stands for outcomes (what you can hope to accomplish, measure, improve or affect) (University Libraries 2008). We find something of this thinking also in van Aken (2005:29) where he says in management design propositions 'the independent variable must describe something of value to the organization, like financial performance'. In IS, Jarvinen (2007) proposes that we should use a goal function for measuring the goodness of a new artefact. The goal function could cover both intended and unintended consequences of the developed artefact.

\section{Practical application}

This principle addresses the 'so what' factor. So you have invented a new database ontology or modelling method. What does that mean? Will the method work? Is it better than other existing methods? In the exterior mode, theorising can be more interesting and acceptable for publication if the phenomena studied include outcomes of IT use. Thus, the research question 'What types of knowledge intermediaries are made use of in organisations' is likely to be of less interest than an alternative question, 'What types of knowledge intermediaries lead to more effective knowledge sharing and dissemination in organisations?'

\section{Principle 3: IT artefacts are systems}

It hardly seems necessary to demonstrate that IT artefacts should be regarded as systems (or tools that are used in dealing with systems). Basic definitions of a computer or information system use words such as input, output, control, feedback and external environment. The first computers appeared after general systems theory had been advanced (Ashby 1956; von Bertalanffy 1968) and relied on many of its concepts. Social-science reference theories commonly talk in terms of social systems. Characteristics of systems are: they are open to and interact with their environment; they acquire new properties through 
emergence and continually evolve; and the parts of a system interact to form a whole that is independent of the separate constituents. Systems concepts include the system-environment boundary, input, output, processes, state, hierarchies, goal directedness and information (Heylighen and Joslyn 1992).

That systems need to be treated differently in scientific reasoning and explanation has been argued by biologists, who are also intimately concerned with systems, albeit those that are animated by life. Nagel (1979:401) gives a comprehensive treatment of this claim and concludes that there are indeed good reasons for differentiating biology from the physical sciences in an essential way: 'One is the dominant place occupied by teleological explanations. The other is the use of conceptual tools uniquely appropriate to the study of systems whose total behaviour is not the resultant of the activities of independent components.'

These considerations apply equally well to the study of computer-based information systems as they do to biology.

Simon has used systems theory concepts extensively in The Sciences of the Artificial (1996). He argues for modern artefacts to be viewed as complex systems and (p. 6) for an artefact as a 'meeting point - an interface' between an "inner" environment, the substance and organization of the artifact itself, and an "outer" environment, the surroundings in which it operates. If the inner environment is appropriate to the outer environment, or vice versa, the artifact will serve its intended purpose.'

\section{Practical application}

This principle has a number of potential applications.

Systems theory itself is likely to be a strong underlying influence on theory development in IS. One example can be found in Weber's (1997) theory of representation. More recently, Braa et al. (2007) used complexity science as a support for theory concerning standard development in a healthcare environment in developing countries.

Levels of analysis issues need to be dealt with in theorising. More recent theoretical models have captured some of the complexity of multi-level influences. For example, Melville et al. (2004) present a model with influences at the level of the external environment, the industry and the firm itself on IT value generation. Burton-Jones and Gallivan (2007) dealt with the problem of the system usage construct at different levels of analysis. Further, researchers often seem to struggle with the need to specify their own level of analysis clearly in theorising and in matching their metrics appropriately to the level of analysis. 
The box and arrow diagrams that are commonly used for research models in quantitative studies can capture only a small part of theories about IT artefacts. These diagrams are usually unidirectional and do not encompass any notions of time or reverse causality. Theorising could be improved if more consideration is given to the temporal aspects of problems concerning systems.

A conjecture is that theorising will more and more be concerned with longitudinal analysis and reverse causality, even in quantitative studies, as more sophisticated statistical tools become available for dealing with these issues. Recent submissions to journals indicate that this trend has begun.

\section{Principle 4: the range of design research approaches should be recognised}

IT artefacts owe their existence to human creativity and imagination coupled with knowledge of the constraints that govern an artefact's operation when it operates in an external real-world environment.

There are many ways of thinking about the design process and innovation and of how designers work in practice (see Cross 2001). Design itself can be thought of as more an art than a science. Atwood et al. (2002) give a useful overview of how the design community thinks about design in general, across many fields. Simon (1996) argues against design as a rational decision process and proposes that human designers - when confronted with myriad design choices - are likely to settle for good or satisfactory solutions rather than optimal ones.

As systems design and implementation are activities performed by IT professionals, methods exist for aiding designers in everyday routine design activity, including the many systems development methodologies. These methods tend to focus on the design of systems to meet predetermined user requirements. This developmental activity, however, is still a creative one, and in practice IT professionals can produce artefacts that are new and interesting from a research point of view. For design theory to be produced, reflecting on what has been done is required (see Schön 1983) and design principles need to be abstracted. This systemisation of knowledge gained through practice is a legitimate academic activity and one that has led to a number of influential design theories. For example, Davenport and Short (1990) abstracted ideas from case studies in 19 companies to first depict the general method of business process redesign. Van Aken (2004:232) refers to this type of activity as an 'extracting case study' or 'best-practice' approach and notes that it has produced a number of very powerful technological rules (design theory), such as the Kanban system and just-in-time approaches. 
When engaging with artefact construction as a research activity, the onus is more on the designer to produce an artefact that is new or novel in some way. In van Aken's terms, this is the 'developing case study' approach. The designscience literature now treats this research activity in some depth. A good overview of design science in IS is provided by Kuechler and Vaishnavi (2008). Design-science research activities are often described in terms of design-buildevaluate cycles and as a problem-solving process. Hevner et al. (2004) utilise a means-end analysis conception of design activity.

Other design research activities that can lead to design knowledge include action research and collaborative clinical research (see van Aken 2005).

It should be noted that experimentation can play a large role in design activities in the sense that designers think of an idea then try it out to see if it works, make a decision then proceed on to other design decisions. This experimentation is part of the process of designing rather than being the experimental method as proposed in science to identify cause-effect relationships. In anything more than a trivial design problem, the designer will make very many design decisions and it would be infeasible to test every design decision point by conducting a formal experiment.

When studying the use of artefacts from the point of view of an observer (the exterior mode), it is well to recall that the theorising should inform subsequent design activities. To this end, one could expect that at least some of the independent variables studied are potentially manipulable by designers.

\section{Practical application}

The different ways in which design theory can be generated from design activities give researchers a number of avenues to pursue. These avenues include extracting design theory from case studies and action research in addition to artefact construction in design-science terms.

\section{Principle 5: different logics are needed}

An issue that has not been much touched on is the question of the underlying logic that is required for design theorising. Simon (1996:114-24) considers whether a special logic of imperatives is needed for design work but concludes it is unnecessary. ${ }^{2}$ He sidesteps the issue, however, in restricting his discussion

2 Standard propositions in logic are statements of fact such as ' $\mathrm{X}$ is the case' (that is, method $\mathrm{X}$ was successful). A prescriptive (hypothetical imperative) statement has the form 'To achieve $\mathrm{Y}$ then do X' (but X might not be the only way of achieving Y). An imperative (categorical imperative) statement says 'Do X'. A predictive statement says 'If $\mathrm{X}$ occurs then $\mathrm{Y}$ will follow'. 
to the use of imperative logic in optimisation methods and means-end analysis, where ordinary mathematical deductive logic can be used to identify the best option from a range of identifiable alternatives.

Designers, however, are not confronted only by optimisation problems, but also by problems in which the range of potential solutions is large and not identifiable at the design point. Such problems cannot normally be solved by deductive logic. An engineer faced with the problem of building a bridge over a ravine has no clear guidance from deductive logic as to which design to implement. About the best that can be done is to think that such and such a design worked in similar situations in the past and reason inductively to assume that the design is likely to work again in this similar situation (engineering analysis indicating that there is no reason to believe it will not work). Thus, as has been pointed out by a number of authors, inductive logic is useful in design research. The extracting case study strategy of van Aken's (2004) is an example. Van Aken followed Bunge (1967) in proposing the development of prescriptive technological rules developed inductively for design knowledge. A technological rule is 'an instruction to perform a finite number of acts in a given order and with a given aim' (Bunge 1967:132). Inductive logic will only lead us to the conclusion, however, that a particular strategy or rule could be used to address a design problem and that it is expected to lead to certain outcomes.

The problem of practical as opposed to theoretical reasoning is addressed in some depth by Edgley (1969), who distinguishes between 'What is the case?' (questions of fact and science) and 'What is to be done?' (questions of action). Edgley shows that prescriptive statements about action do not necessarily follow from descriptive knowledge. To extrapolate, imperative statements about design and action cannot be deduced from scientific knowledge. For example, as a matter of science, one might know that an insecticide kills an insect pest. One cannot deduce from this knowledge that 'in order to kill the insect pest one must use insecticide'; there could be other ways of killing the pest.

The conclusion is that design prescriptions and theory cannot be deduced in any simple and direct manner from reference theories from science or social science. Inductive reasoning from prior experience can, however, be useful.

\section{Practical application}

The hypothetico-deductive method of science does not lead directly to design knowledge and theory; inductive methods can be more useful. The generation of research models in IS deductively from reference theories for quantitative studies should be done with extreme care and not without some degree of 
grounding in IT use in practice. Often it appears that researchers have added variables to their models with only slight attention to their importance in something like a 'shopping-basket' approach.

Reference theories can indicate that a large number of explanatory variables could have some relationship with outcome variables and the inclusion of many variables will lead to more variance being explained in statistical models. This result does not mean that key factors that designers of interventions can manipulate to bring about desired results have been identified. Recent disquiet about the rather ad hoc extensions to the Technology Acceptance Model (TAM) that occur is an illustration of this problem (see the special issue in Journal of the AIS, 2007, vol. 8, titled Quo Vadis TAM?).

\section{Principle 6: different types of theory are needed, including design theory}

The previous discussion has indicated that theory that is needed for design and action will take a different form from other types of theory and will include prescriptive statements such as the technological rules of Bunge (1967) and van Aken (2005). The case for different types of theory depending on the purpose of the theorising is made by Gregor (2006), who distinguishes five interrelated types of theory: Type 1-theory for analysing; Type II - theory for explaining; Type 3-theory for predicting; Type IV - theory for explaining and predicting; Type V-theory for design and action. Gregor and Jones (2007) show in detail the structure and components of a design theory (Type V).

An advance on the reasoning in that prior work is to argue that in a design discipline design theory (Type V) is the ultimate aim. The other types of theorising can contribute to Type $\mathrm{V}$ theory. In contrast, in non-design disciplines such as science, Type $\mathrm{V}$ theory is not needed.

The Type $\mathrm{V}$ knowledge might not take a form that is generally recognised as theory. For example, Davenport and Short's (1980) description of business process redesign is probably not regarded as theorising, yet it has been an extremely influential, well-cited paper and has led to much academic research. Preceding arguments, especially under Principles 4 and 5, have suggested that in many situations, best practice is the best guidance a designer might have, as scientific knowledge from reference disciplines does not necessarily lead to practical design ideas. Some research will recognise this codified best practice under labels such as 'accumulated business wisdom' (see, for example, Melville et al. 2004).

The lingering influence of conventional scientific views of theory leads to charges that papers are 'atheoretic' if they do not include reference theories 
of the non-design type. Novice researchers are nervous about doing work that does not have 'theory'. An illustration is the plight of a $\mathrm{PhD}$ candidate who was investigating project management success. In response to a question as to whether she had considered knowledge of project management methodologies, she replied 'but that's not theory'. Support for a counterargument is provided by published papers that do not contain any theory other than design theory (an example is Iversen et al. 2004, in which design theory is developed from other design theories).

\section{Practical application}

Papers are not necessarily 'atheoretic' if they do not contain reference theory. The IS disciplines will have reached a more mature stage when the theories that are presented are native to IS and concern IT artefacts and their behaviour. Supporting explanations from other disciplines for why and how artefacts lead to the outcomes that they do could be desirable, but are not strictly essential.

\section{Principle 7: mid-range, well-grounded theorising is of particular value}

The quest for high-level 'grand' theories with wide applicability in IT disciplines is a challenging one. Perhaps the most likely prospects remain general systems theory and its derivatives, which provide such general statements as the Law of Requisite Variety: only variety in a system's responses can keep down variety in outcomes when the system is subjected to a set of disturbances (Ashby 1956). Weber (1997) gives a generalised theory of representation, which aims to model the desirable properties of information systems at a deep level and be a theory native to IS. Apart from these few instances, the imprecise nature of knowledge relating to the behaviour of humans interacting with technology and the changing nature of technologies themselves suggest that highly generalised, unchanging laws as can be found in science will be rare in IT design disciplines.

On the other hand, theory by definition must not be too narrow. The solving of one specific design problem or reporting of one case does not mean a design theory has been developed. At least some degree of abstraction and generalisation must occur so that the solution can be generalised to a class of problems and have some applicability in other settings.

An intermediate position is mid-range theory - theory that has moderate coverage and can easily lead to testable hypotheses. Mid-range theory is seen as particularly important for practice disciplines (Merton 1968) such as IS. Similarly, van Aken (2005:238) sees that technological rules are not general 
knowledge, but rather mid-range theories of practice: 'They are only valid for a certain application domain, a range of settings that have key attributes in common with the settings in which the rules were developed and tested.'

Importantly, theory in IT needs to be grounded in practice. As argued under Principle 5, it is difficult or impossible to arrive at design knowledge deductively from a general theory outside the design discipline itself. A theory of interpersonal trust is not going to provide sufficient guidance to develop a design for trustworthy online communication. Knowledge that informs design will also be developed by learning from past designs.

\section{Practical application}

Very general high-level theory for IT is a laudable goal but instances could be rare. Research that produces mid-range theory should be regarded as valuable and publications in journals indicate that this is so. One example is the design theory of Markus et al. (2002) for systems that support emergent knowledge processes: a theory that is generalisable to a particular class of artefacts. Review articles that attempt to pull a number of studies together and advance more general theory are of course also still extremely valuable.

\section{Principle 8: theorising is done in both interior and exterior modes}

The foregoing discussion points to two general modes of research activity and theorising: the interior and exterior modes.

The interior mode is where theorising is done to produce theory for design and action (Type V), with prescriptive statements about how artefacts can be designed, developed and brought into being. The exterior mode, to which we loosely apply the term 'indirect design theorising', includes the other types of theory (Types I to IV), which aim primarily at analysing, describing and predicting what happens as artefacts exist and are used in their external environment.

This division into two modes follows Simon's (1996:7) insights into systems complexity in which the division between the inner and outer environment 'is highly convenient'. The separation of the inner from the outer allows the simplification of tasks. The detail of the inner environment can be hidden when we talk about an artefact attaining its goals and only minimal assumptions might need to be made about the inner environment, as the same end could be achieved by different mechanisms. It is this principle that underlies the mastering of complexity by decomposing hierarchically ordered systems into subsystems in which details of the subsystems' operation are 'hidden'. 
These two modes of theorising are seen as two sides of a coin. Both are needed in the design disciplines of IT and they are complementary to each other. Theory in the exterior mode can include propositions such as 'A system with feature $\mathrm{X}$ will perform better on measure $M$ than a system without feature $X^{\prime}$. If empirical testing shows that this proposition is supported then the proposition can be 'turned around' to give a design proposition: 'If you want to achieve $M$ then include feature $\mathrm{X}$.'

It helps to distinguish the two modes in terms of theorising as they involve different activities and different ways of thinking about theory. Moreover, a single piece of research in a journal article or thesis is likely to include research conducted in either one mode or the other and it is well to consider what is to be regarded as acceptable theorising in each mode.

The principles expounded above have shown the different methods that can be used to produce design ideas in the interior mode (Principle 4). Indirect design theorising in the exterior mode yields ideas about phenomena that can inform design in several ways: through explaining why artefacts work as they do, whether they achieve their stated goals, whether one feature of a designed artefact leads to certain effects, and so on. Going further, however, the argument is also made that theorising on the second side of the coin requires thinking that differs from that common in the pure sciences, in terms of focusing on explanatory factors that can be manipulated and outcome variables that indicate whether artefacts are achieving purposes (Principles 1, 2 and 7). The result will be theory that can be more directly 'turned around' to yield design ideas and principles - a desirable state of affairs in an applied discipline.

\section{Practical application}

Researchers are likely to work in only one mode at a time and our community of scholars needs to recognise how much can reasonably be expected in a single article or thesis. A researcher who has devoted a great deal of effort to showing how a new artefact can work - and in showing that it is a novel artefact - might not have the time and effort to do the comprehensive evaluation that would be expected if he/she was working in the exterior mode assessing an artefact constructed by someone else. The IT design communities would do well to reflect and define their expectations in this respect.

Researchers working in the interior mode and theorising about how artefacts can be constructed should be aware of the range of approaches available to them - not just the design-science approaches of design/build/evaluate, but also the extraction of design principles from case studies.

Researchers working in the exterior mode can improve their theorising by study of a number of the principles: focusing on an IT artefact (Principle 1); 
considering outcomes of use (Principle 2); using systems concepts (Principle 3); and accepting that inductive theory building and mid-range theorising native to IS are valuable (Principles 5 and 7).

\section{Concluding remarks}

This chapter addresses a complex issue - that of theory building — and it does it from the point of view of a design discipline, a perspective that has been little considered. Thus, the arguments made are advanced for discussion and to further debate, rather than being regarded as fixed and certain ideas. There are many new ideas appearing in the literature of design, which as a study of the design of complex artefacts dates back only about 50-60 years. It is expected that it will be some time before a common understanding and means of describing our problems emerge. This chapter is just one step along the path.

A limitation of the chapter is that it does not cover some of the necessary and more generally accepted features of theory-building and research methods. Thus, the advantages and limitations of different research approaches are not discussed. At heart, the chapter is about logical reasoning; the principles derived are arrived at by logical extension from the defining characteristics of IT and its nature as a design discipline.

The contribution of the chapter is that it provides a high-level framework for thinking about the different types of theorising in the paradigm of science versus that of design. Many of the ideas in the chapter stem from Simon's seminal work (1996), yet there are differences - particularly in the identification of the need for different logics. Further, Simon did not give much thought to the actual process of theorising and both he and subsequent writers have not explicated the special features of theorising in the exterior mode in a design discipline.

The ideas with regard to practical application of each principle are in part conjectures. In future work, it would be valuable to explore whether the principles appear, even implicitly, in what could be regarded as 'good' theorising or seminal work in IS.

Further work could also usefully be done to make the study of the processes of theory building more transparent. Space precludes such examination in this chapter. 


\section{References}

Ashby, W. R. 1956, An Introduction to Cybernetics, Chapman \& Hall, London.

Atwood, M., McCain, K. and Williams, J. 2002, 'How does the design community think about design?', Symposium on Designing Interactive Systems, pp. 125-132

Benbasat, I. and Zmud, R. 2003, 'The identity crisis within the IS discipline: defining and communicating the discipline's core properties', MIS Quarterly, vol. 27, no. 2, pp. 183-94.

Bourgeois, L. 1979, 'Toward a method of middle-range theorizing', Academy of Management Review, vol. 4, pp. 443-7.

Braa, J., Hanseth, O., Heywood, A., Mohamamd, W. and Shaw, V. 2007, 'Developing health information systems in developing countries: the flexible standards strategy', MIS Quarterly, vol. 31, no. 2, pp. 381-402.

Bunge, M. 1967, Scientific Research II: The search for truth, Springer Verlag, Berlin.

Burton-Jones, A. and Gallivan, M. J. 2007, 'Towards a deeper understanding of system usage in organizations: a multilevel perspective', MIS Quarterly, vol. 31, no. 4 (December), pp. 657-79.

CC2005 2005, Computing Curricula 2005. The overview report, Association of Computing Machinery, New York, and IEEE Computer Society, Washington, DC.

Cross, N. 2001, 'Designerly ways of knowing: design discipline versus design science', Design Issues, vol. 17, no. 3, pp. 49-55.

Davenport, T. and Short, J. 1990, 'The new industrial engineering: information technology and business process redesign', Sloan Management Review, vol. 31 , no. 4 , pp. 11-27.

Dilthey, W. 1883, 'Introduction to the human sciences', Stanford Encyclopedia of Philosophy, Stanford University Press, Calif., <plato.stanford.edu/entries/ dilthey/>

Edgley, R. 1969, Reason in Theory and Practice, Hutchinson University Library, London.

Glaser, B. and Strauss, A. L. 1967, The Discovery of Grounded Theory: Strategies for qualitative research, Aldine Publishing Company, New York. 
Godfrey-Smith, P. 2003, Theory and Reality, University of Chicago Press, Ill.

Goldkuhl, G. 2004, 'Design theories in information systems - a need for multigrounding', Journal of Information Technology Theory and Application, vol. 6, no. 2 , pp. $59-72$.

Gregor, S. 2006, 'The nature of theory in information systems', MIS Quarterly, vol. 3, no. 30, pp. 611-42.

Gregor, S. and Jones, D. 2007, 'The anatomy of a design theory', Journal of the Association of Information Systems, vol. 8, no. 5, article 2, pp. 312-35.

Heidegger, M. 1993, 'The question concerning technology', Basic Writings, Harper, San Francisco, pp. 311-41.

Hevner, A., March, S., Park, J. and Ram, S. 2004, 'Design science in information systems research', MIS Quarterly, vol. 28, no. 1, pp. 75-105.

Heylighen, F. and Joslyn, C. 1992, 'Systems theory', in F. Heylighen, C. Joslyn and V. Turchin (eds), Principia Cybernetica Web, Principia Cybernetica, Brussels, viewed August 2008, <http://pespmcl.vub.ac.be/systheor.html>

Hooker, R. 1993, 'Aristotle: the four causes - physics II.3', viewed 15 March 2007, <http://www.wsu.edu:8080/ dee/GREECE/4CAUSES.HTM>

Iivari, J. 2003, 'Towards information systems as a science of meta-artifacts', Communications of the AIS, vol. 12, no. 37 (November), pp. 568-81.

Iversen, J., Mathiassen, L. and Nielsen, P. 2004, 'Managing process risk in software process improvement: an action research approach', MIS Quarterly, vol. 28, no. 3, pp. 395-434.

Jarvinen P. 2007, 'On reviewing results of design research', ECIS 2007, St Gallen, Switzerland, 7-9 June.

Kaplan, A. 1964, The Conduct of Enquiry, Chandler, San Francisco.

Kuechler, W. and Vaishnavi, V. 2008, 'The emergence of design science research in information systems in North America', Journal of Design Research, vol. 7, no. 1, pp. 1-16.

March, S. T. and Smith, G. F. 1995, 'Design and natural science research on information technology', Decision Support Systems, no. 15, pp. 251-66.

Markus, M., Majchrzak, L. A. and Gasser, L. 2002, 'A design theory for systems that support emergent knowledge processes', MIS Quarterly, vol. 26, no. 3, pp. 179-212. 
Melville, N., Kraemer, K. and Gurbaxani, V. 2004, 'Review: information technology and organizational performance: an integrative model of IT business value', MIS Quarterly, vol. 28, no. 2, pp. 283-322.

Merton, R. 1968, On Theoretical Sociology, Free Press, New York.

MIS Quarterly 2008, MIS Quarterly Central Home Page, viewed August 2008, $<$ http://www.misq.org/>

Nagel, E. 1979, The Structure of Science, Hackett Publishing, Indianapolis.

O'Hear, A. 1989, Introduction to the Philosophy of Science, Clarendon Press, Oxford.

Orlikowski, W. J. and Iacono, C. S. 2001, 'Research commentary: desperately seeking the "IT" in IT research - a call to theorizing the IT artifact", Information Systems Research, vol. 12, no. 2, pp. 121-34.

Parry, R. 2007, 'Episteme and techne', Stanford Encyclopedia of Philosophy, Stanford University Press, Calif., viewed November 2007, <http://plato. stanford.edu/entries/episteme-techne/>

Popper, K. 1980, The Logic of Scientific Discovery, Unwin Hyman, London.

Scharff, R. C. and Dusek, V. 2003, Philosophy of Technology: The Technological condition. An anthology, Blackwell Publishing, Malden, Mass.

Schön, D. 1983, The Reflective Practitioner, Basic Books, New York.

Simon, H. 1996, The Sciences of the Artificial, Third edition, MIT Press, Cambridge, Mass.

Strasser, S. 1985, Understanding and Explaining Basic Ideas Concerning the Humanity of the Human Sciences, Duquesne University Press, Pittsburgh.

University Libraries 2008, Real-Time EBM Program: The P I C O Model, viewed August 2008, <http://www4.umdnj.edu/camlbweb/ebm/picomodel.htm>

van Aken, J. 2004, 'Management research based on the paradigm of the design sciences: the quest for field-tested and grounded technological rules', Journal of Management Studies, vol. 41, no. 2, pp. 219-46.

van Aken, J. 2005, 'Management research as a design science: articulating the research products of mode 2 knowledge production in management', British Journal of Management, vol. 16, no. 1, pp. 19-36. 
Venable, J. 2006, 'The role of theory and theorising in design science research', First International Conference on Design Science Research in Information Systems and Technology, Claremont, Calif., pp. 1-18.

von Bertalanffy, L. 1968, General System Theory, Braziller, New York.

Weber, R. 1987, 'Toward a theory of artifacts: a paradigmatic base for information systems research', Journal of Information Systems, vol. 1, no. 1 (Spring), pp. 3-19.

Weber, R. 1997, Ontological Foundations of Information Systems, Coopers \& Lybrand, Melbourne.

Weick, K. 1989, 'Theory construction as disciplined imagination', Academy of Management Review, vol. 14, no. 4, pp. 516-31. 